\section{Unexpected complication of septal ablation 22 years later, septal diverticule with thrombus}

\author{
İrem Okçular Sezer (D), Tuğrul Okay1 (D)
}

Department of Cardiology, Acıbadem Atakent Hospital; Istanbul-Turkey

1Department of Cardiology, Acıbadem International Hospital; İstanbul-Turkey

\section{Introduction}

The first alcohol septal ablations (ASA) in the treatment of patients with hypertrophic cardiomyopathy were reported by Sigwart (1) in 1995. Since then, ASA has been accepted as being comparable with myectomy in patients who do not show any relief of symptoms with medical therapy. The complications related to the procedure, including septal rupture/iatrogenic ventricular septal defect (2) were described in 26 years' time. Here, we report a case of ventricular diverticule with thrombus, which was recognized 22 years after ASA.

\section{Case Report}

A 37-year-old woman presented to the hospital with class 3 symptoms in 1997. Echocardiographic evaluation showed hypertrophic obstructive cardiomyopathy with a septal thickness of 34 $\mathrm{mm}$ and a resting left ventricular outflow tract gradient of 80/25 $\mathrm{mm} \mathrm{Hg}$. Coronary angiography was normal with a well-developed proximal septal branch (Fig. 1). ASA was performed with 5 $\mathrm{mL}$ of alcohol infusion, which was the suggested dose in those years; $2-3 \mathrm{~mL}$ is preferred nowadays. As the alcohol dosage was high, the extent of the infarct was prone to be deeper and wider. Atrioventricular dissociation occurred following the procedure, which resolved with intermittent temporary pacemaker support for 3 days. The postprocedural left ventricular outflow tract gradient was $20 / 7 \mathrm{~mm} \mathrm{Hg}$ and the patient was asymptomatic. In the $6^{\text {th }}$ month of the procedure, the septal thickness was reported to decrease to $24 \mathrm{~mm}$ (Video 1). It was the first case performed in Turkey (3).

Since then, the patient was being followed with medical therapy without any symptoms. Surveillance echocardiographic follow-ups reported no complication or abnormality. Cardiovascular magnetic resonance imaging (CMR) was planned to evaluate the progress of the disease and the fibrosis level as the patient had begun to complain of effort dyspnea.

The most recent CMR was performed in July 2019 (Siemens 1.5T). Asymmetrical septal hypertrophy was visualized with a maximal septal thickness of $19 \mathrm{~mm}$ in the inferior septum. Oddly, in the cine images, there was a diverticular recess in the mid septum, which was accepted as related to ASA. The dimensions were $10 \times 7 \mathrm{~mm}$ in the end-diastolic images and $12 \times 5 \mathrm{~mm}$ in the end-systolic images. Fortunately, the wall thickness at the tip of

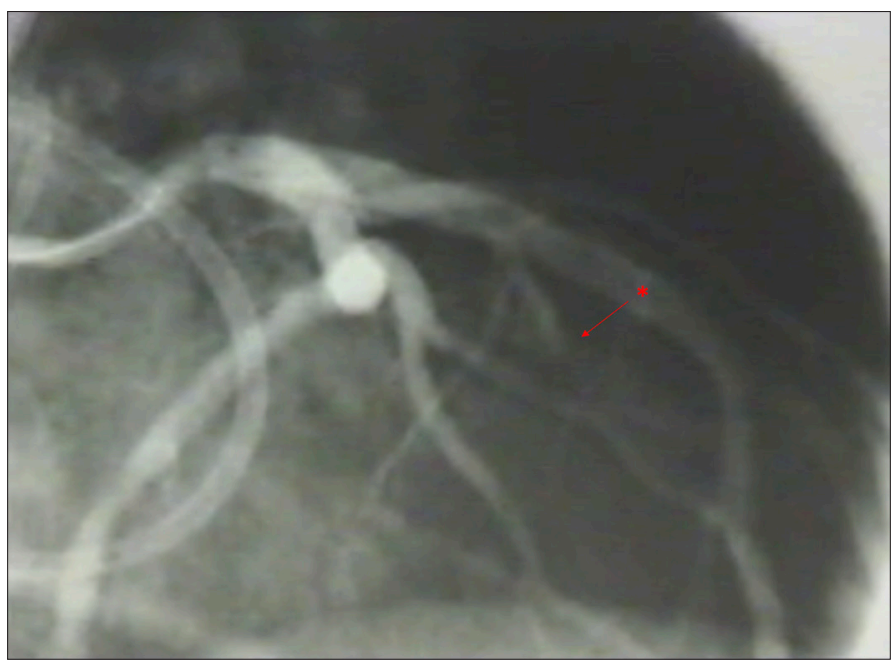

Figure 1. Coronary angiography with a well-developed proximal septal branch

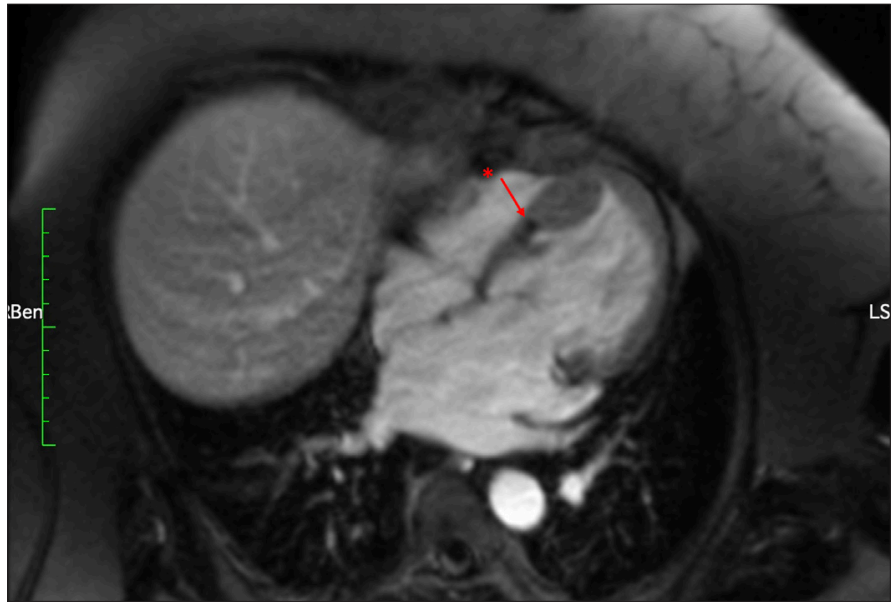

Figure 2. Early post-contrast images showing a hypointense small mass at the tip of the diverticule, which matched well with thrombus formation

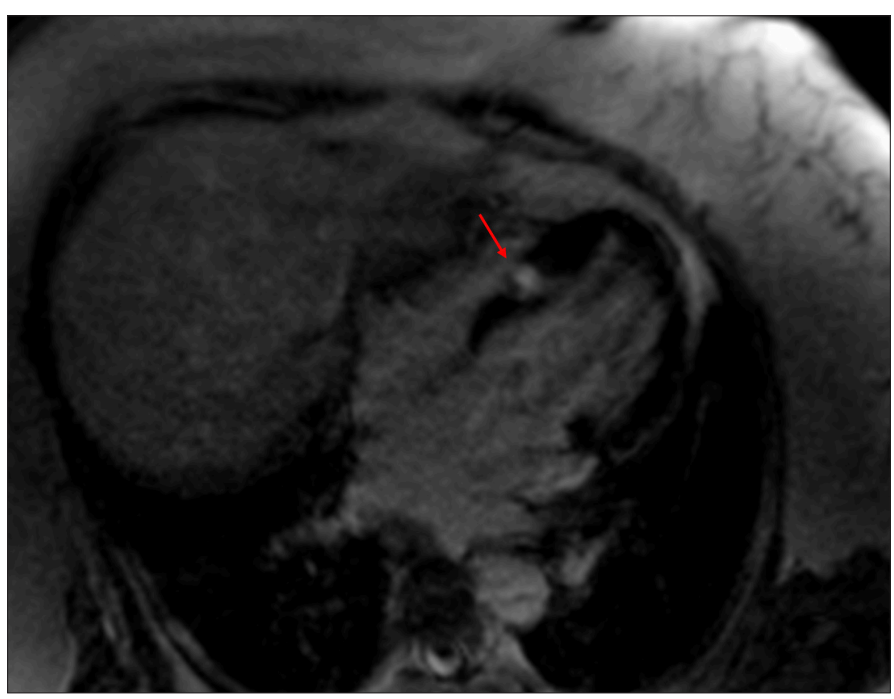

Figure 3. In delayed enhanced images, a dense scar tissue is seen around the diverticular recess 


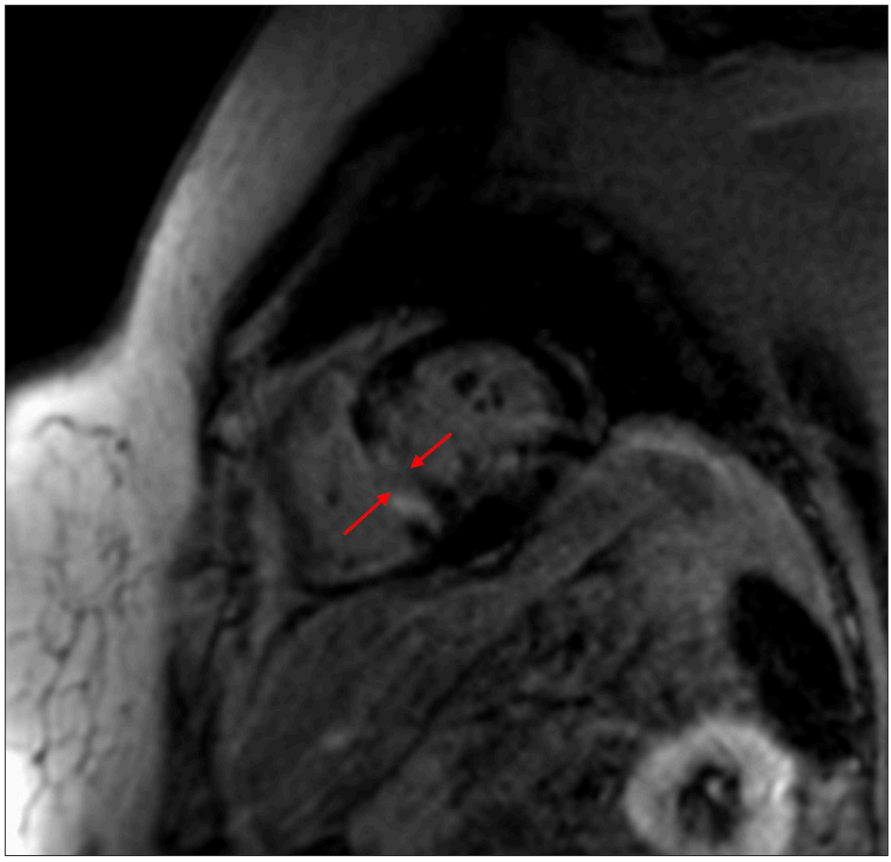

Figure 4. In delayed enhanced images, a dense scar tissue is seen around the diverticular recess

the diverticule was $2 \mathrm{~mm}$, and no ventricular septal defect was detected at that level (Videos 2, 3, and 4).

After gadolinium injection, early post contrast images (1-3 min, Tl: $450 \mathrm{msn}$ ) showed a hypointense, small mass at the tip, which matched well with thrombus formation. In late-contrast images (7-15 min), the scar tissue could have been visualized only around the diverticular recess as a result of the procedure (Fig. 2-4).

\section{Discussion}

CMR is used extensively in patients with hypertrophic cardiomyopathy. It is particularly helpful in newly-diagnosed patients to confirm diagnosis and visualize the fibrosis/scar tissue for deciding the requirement of further treatment modalities. Our case demonstrates that CMR imaging can add extra and sometimes unpredicted information, even in patients who have been followed for years with echocardiography. CMR is indisputably better than echocardiography, particularly in the visualization of a small-size thrombus (4). CMR is also important in evaluating the achievements of the ASA procedure.

\section{Conclusion}

Echocardiography is the first-line follow-up imaging modality; however, the disadvantage of its resolution makes it prone to miss some pathologies. CMR is a better option for finer details and tissue differentiation.

Informed consent: Written informed consent was obtained from the patient for the publication of this case report and any accompanying images.

Video 1. At the $6^{\text {th }}$ month of alcohol septal ablations, the septal thickness was measured at $24 \mathrm{~mm}$ with no septal abnormality

Videos 2, 3, and 4. Four-chamber, three-chamber, and short axis cine views (steady-state free precession) of the diverticular recess.

\section{References}

1. Sigwart U. Non-surgical myocardial reduction for hypertrophic obstructive cardiomyopathy. Lancet 1995; 346: 211-4. [Crossref]

2. Steggerda RC, Damman K, Balt JC, Liebregts M, ten Berg JM, van den Berg MP. Periprocedural complications and long-term outcome after alcohol septal ablation versus surgical myectomy in hypertrophic obstructive cardiomyopathy: a single-center experience. JACC Cardiovasc Interv 2014; 7: 1227-34. [Crossref]

3. Inanir S, Okay T, Ozer C, Mogolkoc M, Kahraman M, Dincer H, et al. Scintigraphic evaluation of nonsurgical septal reduction therapy in patients with hypertrophic obstructive cardiomyopathy with symptoms refractory to medical treatment. European $\mathrm{J}$ Nuclear Medicine 1999; 26: 1063.

4. Srichai MB, Junor C, Rodriguez LL, Stillman AE, Grimm RA, Lieber $M L$, et al. Clinical, imaging, and pathological characteristics of left ventricular thrombus: a comparison of contrast-enhanced magnetic resonance imaging, transthoracic echocardiography, and transesophageal echocardiography with surgical or pathological validation. Am Heart J 2006; 152: 75-84. [Crossref]

Address for Correspondence: Dr. İrem Okçular Sezer, Acıbadem Atakent Hastanesi, Kardiyoloji Kliniği,

İstanbul-Türkiye

Phone: +90 5324108008

E-mail: iremokcular@yahoo.com

(C) Copyright 2021 by Turkish Society of Cardiology Available online at www.anatoljcardiol.com DOI:10.5152/AnatolJCardiol.2021.56 